\title{
EFFECT OF BAFFLE PLATE ON THE PERFORMANCE OF A TRIANGULAR BUILT-IN-STORAGE SOLAR WATER HEATER
}

\author{
S. C. KAUSHIK, R. KUMAR and H. P. GARG \\ Centre for Energy Studies, Solar Refrigeration Laboratory, Indian Institute of Technology, Delhi, \\ Hauz Khas, New Delhi-110 016, India
}

(Received 25 September 1993; received for publication 23 November 1994)

\begin{abstract}
The triangular design of a solar water heater not only enhances the overall gain to the system but also improves the natural convection between the absorbing plate and the water, leading to better performance of the system. A night insulation cover is used at the top surface of the heater to reduce the losses from the system during the off-sunshine hours. Another way to reduce the losses from the system is by using an insulating baffle plate in the tank. This plate divides the tank water into two portions, the water above this plate is known as the upper column and below is known as the lower column. The water of the two columns is in contact with each other with the help of the incoming and outgoing vents provided in the baffle plate. This plate also suppresses losses from the lower column during the off-sunshine hours. In this paper, we have studied the effect of a baffle plate on the performance of a triangular built-in-storage solar water heater. To obtain the thermal behavior of the system, the energy balance equations are written at the different nodes, and the well-known finite difference forward time step marching technique is used for their solution. The proposed system is studied by varying the vent area, the water mass in the two columns and under a constant flow rate for different durations. The effects of the thermal conductivity and thickness of the baffle plate on the water temperature are also investigated. It is found that the presence of the baffle plate greatly improves the system performance during off-sunshine hours.
\end{abstract}

\begin{tabular}{|c|c|c|c|}
\hline & Baffle plate & Transient performance & Collection-cum-storage \\
\hline
\end{tabular}

\section{NOMENCLATURE}

$A_{1}=$ Area of absorbing plate $\left(\mathrm{m}^{2}\right)$

$A_{2}=$ Area of baffle plate $\left(\mathrm{m}^{2}\right)$

$A_{3}=$ Vent-area in baffle plate $\left(\mathrm{m}^{2}\right)$

$A_{\mathrm{b}}=$ Area of bottom surface $\left(\mathrm{m}^{2}\right)$

$c_{\mathrm{w}}=$ Specific heat of water $\left(\mathrm{J} \mathrm{kg}^{-1}{ }^{\circ} \mathrm{C}^{-1}\right)$

$h_{1}=$ Heat transfer coefficient between absorbing plate and glass $\left(\mathrm{W} \mathrm{m}^{-2} \mathrm{C}^{-1}\right)$

$h_{2}=$ Heat transfer coefficient between absorbing plate and upper water column $\left(\mathrm{W} \mathrm{m}^{-2}{ }^{\circ} \mathrm{C}^{-1}\right)$

$h_{3}=$ Heat transfer coefficient between upper and lower water column $\left(\mathrm{W} \mathrm{m}^{-2} \mathrm{C}^{-1}\right)$

$h_{4}=$ Total heat loss coefficient from glass to ambient $\left(\mathrm{W} \mathrm{m}^{-2} \mathrm{C}^{-1}\right)$

$K_{\mathrm{b}}=$ Thermal conductivity of baffle plate $\left(\mathrm{W} \mathrm{m}^{-1} \mathrm{C}^{-1}\right)$

$L_{\mathrm{b}}=$ Thickness of baffle plate $(\mathrm{m})$

$m_{\mathrm{g}}=$ Mass of glass cover $(\mathrm{kg})$

$m_{\mathrm{p}}=$ Mass of absorbing plate $(\mathrm{kg})$

$m_{\mathrm{w} 1}=$ Water mass in upper column $(\mathrm{kg})$

$m_{\mathrm{w} 2}=$ Water mass in lower column $(\mathrm{kg})$

$\dot{m}=$ Mass flow rate $\left(\mathrm{kg} \mathrm{h}^{-1}\right)$

$S(t)=$ Solar intensity $\left(\mathrm{W} \mathrm{m}^{-2}\right)$

$T_{\mathrm{a}}=$ Ambient temperature $(\mathrm{C})$

$T_{\mathrm{p}}=$ Plate temperature ( $\left.\mathrm{C}\right)$

$T_{\mathrm{w} 1}=$ Upper column water temperature ('C)

$T_{\mathrm{w} 2}=$ Lower column water temperature (C)

$\alpha_{\mathrm{g}}=$ Absorptivity of glass

$\tau_{g}=$ Transmittivity of glass

$\alpha_{\mathrm{p}}=$ Absorptivity of plate

\section{INTRODUCTION}

In earlier work [1-4], it is seen that the overall performance of a triangular built-in-storage type solar water heater is better than that of the conventional water heater. The first advantage of the 
triangular design is that it will gain more solar energy than the conventional water heater during the sunshine hours, and the other advantage of the triangular design is that it will enhance the natural convection between the absorbing surface and the water in the tank, leading to a better performance of the system. As the temperature of the system increases, the losses from the system are also increased. To overcome this problem, it is suggested that either an insulating cover material above the absorbing surface or a baffle plate [5-7] inside the tank be used. The baffle plate divides the tank into two portions, viz. an upper column and a lower column, the upper column is in direct contact with the absorbing plate, whereas the upper and lower water columns are in contact with each other through vents provided in the baffle plate for incoming and outgoing water. The transfer of heat from the upper water column to the lower is by conduction through the baffle plate and by convection through the vents. To obtain the thermal performance of the system, the energy balance equations are written for the different nodes. The whole system is divided into four nodes, viz. the glass, the plate, the water in the upper column and the water in the lower column. For solution of the differential equations, the well-known finite difference forward time step marching technique is used. In this paper, the performance of the system is studied by changing the vent area and the mass ratio between the two columns and under a constant flow rate for different durations. The effects of the thermal conductivity and thickness of the baffle plate on the water temperatures in the two columns are also studied.

\section{DESIGN OF THE SYSTEM}

Figure 1 shows the cross-sectional view of the triangular built-in-storage solar water heater with a baffle plate. The steel tank is made of 20 gauge galvanized iron sheet and has a volume of 981 . The area of the absorbing surface is $1 \mathrm{~m}^{2}$ and is painted by an ordinary black-board paint to facilitate the absorption of the solar radiation incident on it. In order to reduce the losses from the system, a $5 \mathrm{~cm}$ thick layer of fiberglass wool is provided at the bottom and in the sides of the tank. A glass cover of $3 \mathrm{~mm}$ thickness is provided above the absorbing surface with an air gap of $3 \mathrm{~cm}$. An insulating baffle plate is provided inside the tank which divides the tank into two portions, viz. an upper column and a lower column. The upper and lower water columns are in contact through the vents provided in the baffle plate. The mass ratio in the two water columns varies with the position of the baffle plate in the tank, but the total water mass in the tank remains constant. The solar energy, after passing through the glass and air gap, is incident on the absorbing plate. As the solar energy is absorbed by the absorbing plate, its temperature rises, and the thermal energy is transferred to the upper water column. The transfer of heat from the upper water column to the lower is through the vents provided in the baffle plate.

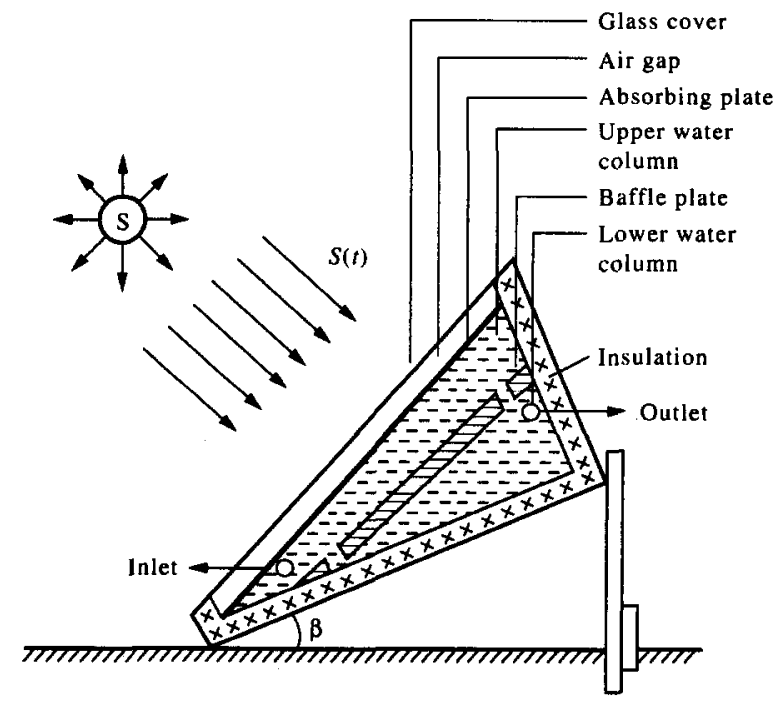

Fig. 1. Schematic diagram of triangular built-in-storage solar water heater with baffle plate. 


\section{THERMAL ANALYSIS}

The solar radiation falling on the absorbing surface is partly absorbed by it and partly reflected back to the surroundings. The solar energy absorbed by the plate is transferred to the water in the upper column. The transfer of heat from the upper water column to the lower is by conduction through the baffle plate and convection through the vents. So, the temperature of the lower water column is increasing, and this process is continued during the sunshine hours. To obtain the thermal performance of the system, the total system is divided into four nodes, viz. the glass, the plate, the upper water column and the lower water column. The energy balance equations for the different nodes are written as:

For the glass

$$
m_{\mathrm{g}} c_{\mathrm{g}}\left(\mathrm{d} T_{\mathrm{g}} / \mathrm{d} t\right)=\alpha_{\mathrm{g}} S(t) A_{1}+h_{1} A_{\mathrm{l}}\left(T_{\mathrm{p}}-T_{\mathrm{g}}\right)-h_{4} A_{1}\left(T_{\mathrm{g}}-T_{\mathrm{a}}\right)
$$

where $h_{1}$ is the convective heat transfer coefficient from the plate to glass and $h_{4}$ is the heat loss coefficient from the glass to the surroundings.

For the plate

$$
m_{\mathrm{p}} c_{\mathrm{p}}\left(\mathrm{d} T_{\mathrm{p}} / \mathrm{d} t\right)=\left(\alpha_{\mathrm{g}} \tau_{\mathrm{p}}\right) S(t) A_{1}-h_{1} A_{1}\left(T_{\mathrm{p}}-T_{\mathrm{g}}\right)-h_{2} A_{\mathrm{l}}\left(T_{\mathrm{p}}-T_{\mathrm{wl}}\right)
$$

where $h_{2}$ is the convective heat transfer coefficient from the plate to the upper water column.

For the upper water column

$m_{\mathrm{w} 1} c_{\mathrm{w}}\left(\mathrm{d} T_{\mathrm{w} 1} / \mathrm{d} t\right)=h_{2} A_{1}\left(T_{\mathrm{p}}-T_{\mathrm{w} 1}\right)-h_{3} A_{3}\left(T_{\mathrm{w} 1}-T_{\mathrm{w} 2}\right)-\left(K_{\mathrm{b}} / L_{\mathrm{b}}\right)\left(T_{\mathrm{w} 1}-T_{\mathrm{w} 2}\right) A_{2}-\dot{m} c_{\mathrm{w}}\left(T_{\mathrm{w} 1}-T_{\mathrm{in}}\right)$

where the third term in the right hand side of the above equation represents the heat transfer by conduction from the upper water column to the lower.

For the lower water column

$$
\begin{aligned}
m_{\mathrm{w} 2} c_{\mathrm{w}}\left(\mathrm{d} T_{\mathrm{w} 2} / \mathrm{d} t\right)=h_{3} A_{3}\left(T_{\mathrm{w} 1}-T_{\mathrm{w} 2}\right)+\left(K_{\mathrm{b}} / L_{\mathrm{b}}\right)\left(T_{\mathrm{w} 1}-\right. & \left.T_{\mathrm{w} 2}\right) A_{2} \\
& \quad-U_{\mathrm{be}} A_{\mathrm{be}}\left(T_{\mathrm{w} 2}-T_{\mathrm{a}}\right)-\dot{m} c_{\mathrm{w}}\left(T_{\mathrm{w} 2}-T_{\mathrm{in}}\right)
\end{aligned}
$$

where the $T_{\text {in }}$ in equations (3) and (4) indicates the inlet water temperature.

The average daily efficiency of the solar water heater is defined as

$$
\eta=\left[m_{\mathrm{w}} c_{\mathrm{w}}\left(T_{\mathrm{w}}-T_{\mathrm{u}}\right)+\int_{0}^{t^{\prime}} \dot{m} c_{\mathrm{w}}\left(T_{\mathrm{w}}-T_{\mathrm{in}}\right) \mathrm{d} t\right] /\left[\int_{0}^{t} S(t) \mathrm{d} t\right]
$$

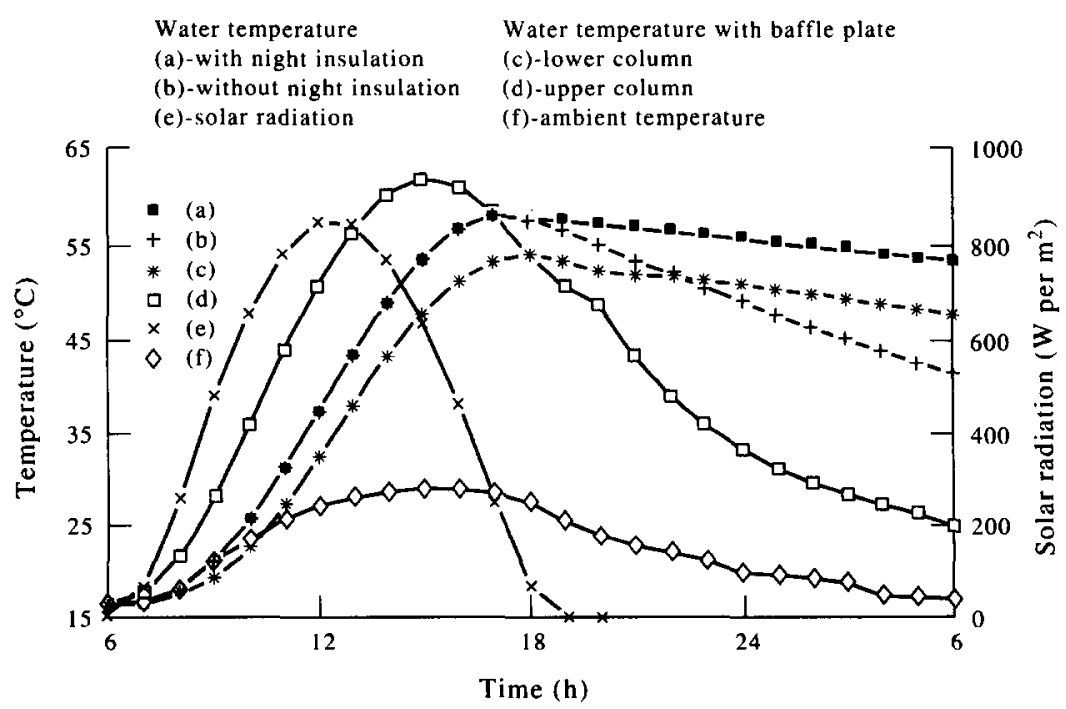

Fig. 2. Variation in water temperature with and without baffle plate, solar radiation and ambient temperature. 
where the numerator shows the total useful heat available from the system, and integration in the numerator is over the time period for which hot water is withdrawn from the heater, and the integration in the denominator is for the sunshine duration. The hourly values of solar radiation incident on the horizontal at I.I.T. Delhi for a clear spring day is used for calculating the hourly values of solar flux incident on the absorbing surface by using the well-known Liu and Jordan equations [8]. The values of the solar radiation and ambient temperature are plotted in Fig. 2 .

It is assumed that in the beginning the temperature of the whole system is equal to the ambient temperature.

To obtain the thermal behavior of the system, we used the finite difference forward time step marching technique. In this technique, $(\mathrm{d} T / \mathrm{d} t)$ is replaced by $\left[\left(T^{i+1}-T^{i}\right) / \Delta t\right]$, where $T^{i}$ and $T^{i+1}$ are the values of the water temperature just before and after the time interval $\Delta t$.

For the purpose of thermal analysis, the coupled differential equations (1-4) are written in their difference form as below

$$
\begin{gathered}
T_{\mathrm{g}}^{\prime}=T_{\mathrm{g}}+\left(\Delta t / m_{\mathrm{g}} c_{\mathrm{g}}\right)\left[\alpha_{\mathrm{g}} S(t) A_{1}+h_{1} A_{1}\left(T_{\mathrm{p}}-T_{\mathrm{g}}\right) A_{1}-h_{4} A_{1}\left(T_{\mathrm{g}}-T_{\mathrm{a}}\right)\right] \\
T_{\mathrm{p}}^{\prime}=T_{\mathrm{p}}+\left(\Delta t / m_{\mathrm{p}} c_{\mathrm{p}}\right)\left[\alpha_{\mathrm{p}} \tau_{\mathrm{g}} S(t) A_{1}-h_{1} A_{1}\left(T_{\mathrm{p}}-T_{\mathrm{g}}\right)-h_{2} A_{1}\left(T_{\mathrm{p}}-T_{\mathrm{w} 1}\right)\right] \\
T_{\mathrm{w} 1}^{\prime}=T_{\mathrm{w} 1}+\left(\Delta t / m_{\mathrm{w} 1} c_{\mathrm{w} 1}\right)\left[h_{1} A_{1}\left(T_{\mathrm{p}}-T_{\mathrm{w} 1}\right)-h_{3} A_{3}\left(T_{\mathrm{w} 1}-T_{\mathrm{w} 2}\right)\right. \\
\left.-\left(K_{\mathrm{b}} / L_{\mathrm{b}}\right) A_{2}\left(T_{\mathrm{w} 1}-T_{\mathrm{w} 2}\right)-\dot{m} c_{\mathrm{w}}\left(T_{\mathrm{w} 1}-T_{\mathrm{in}}\right)\right] \\
T_{\mathrm{w} 2}^{\prime}=T_{\mathrm{w} 2}+\left(\Delta t / m_{\mathrm{w} 2} c_{\mathrm{w}}\right)\left[h_{3} A_{3}\left(T_{\mathrm{w} 1}-T_{\mathrm{w} 2}\right)+\left(K_{\mathrm{b}} / L_{\mathrm{b}}\right) A_{2}\left(T_{\mathrm{w} 1}-T_{\mathrm{w} 2}\right)-\dot{m} c_{\mathrm{w}}\left(T_{\mathrm{w} 2}-T_{\mathrm{in}}\right)\right]
\end{gathered}
$$

\section{RESULTS AND DISCUSSION}

In the beginning, the calculations are started by using the initial conditions, and thereafter, the various nodal temperatures are progressively calculated after the first time step $\Delta t$. We have found that a value of $10 \mathrm{~s}$ for $\Delta t$ gives a converging solution of the coupled differentional equations (1-4).

Figure 2 shows the water temperature in the tank with and without the baffle plate, without a baffle plate but having a night insulation cover, solar radiation available on the horizontal surface and the ambient temperature. The maximum water temperature of about $61^{\circ} \mathrm{C}$ is achieved in the upper water column at $17 \mathrm{~h}$, and in the same column, the next day morning water temperature is about $10^{\circ} \mathrm{C}$ higher than the ambient temperature. In the lower water column, the water is available above $50^{\circ} \mathrm{C}$ for more than $12 \mathrm{~h}$, and the next day morning water temperature, in the same column, is about $30^{\circ} \mathrm{C}$ higher than the ambient temperature. Although the maximum water temperature in the tank without the baffle plate is $4-5^{\circ} \mathrm{C}$ higher than the maximum water temperature in the lower water column, during the off-sunshine hours, the water temperature in the lower water column is always greater than the water temperature in the tank without the baffle plate.

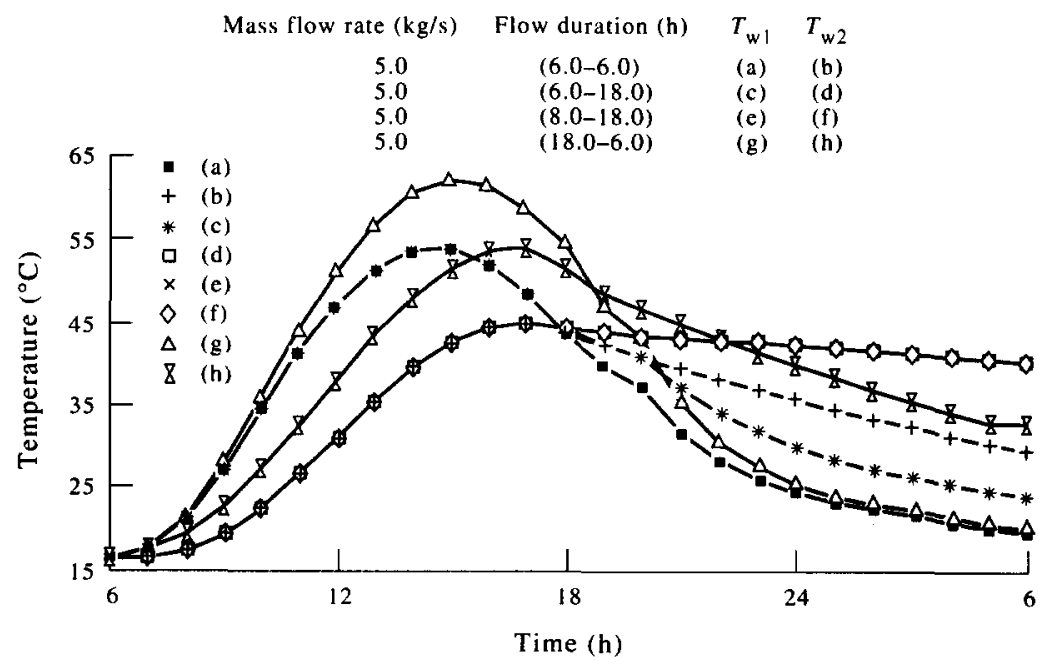

Fig. 3. Variation in water temperature under constant flow rate for different durations. 


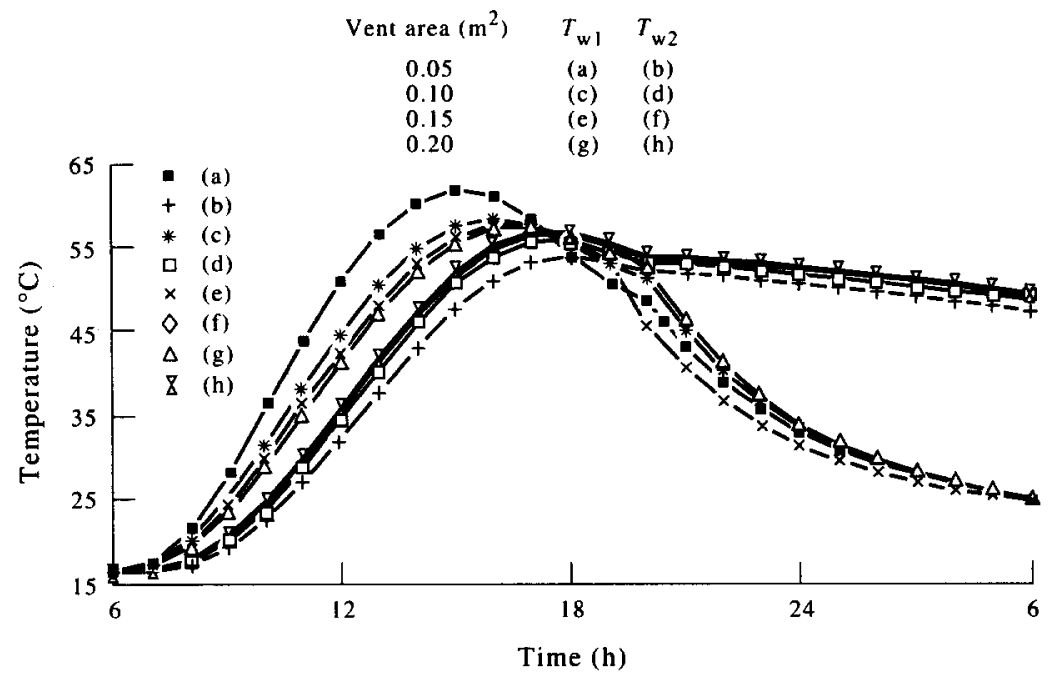

Fig. 4. Variation in water temperature with varying vent area.

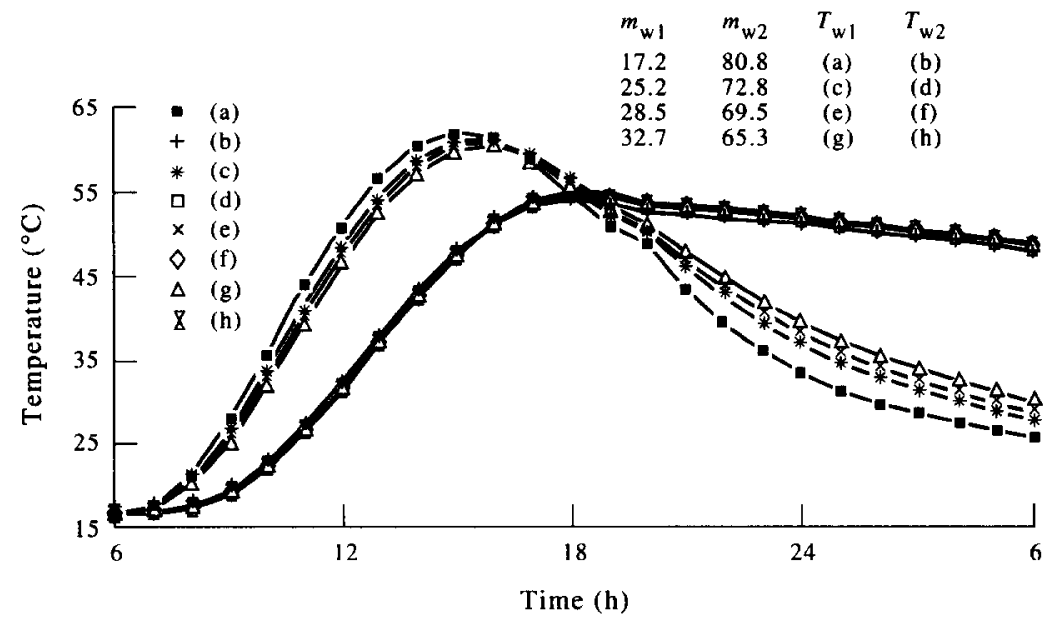

Fig. 5. Variation in water temperature by changing the mass ratio in two columns.

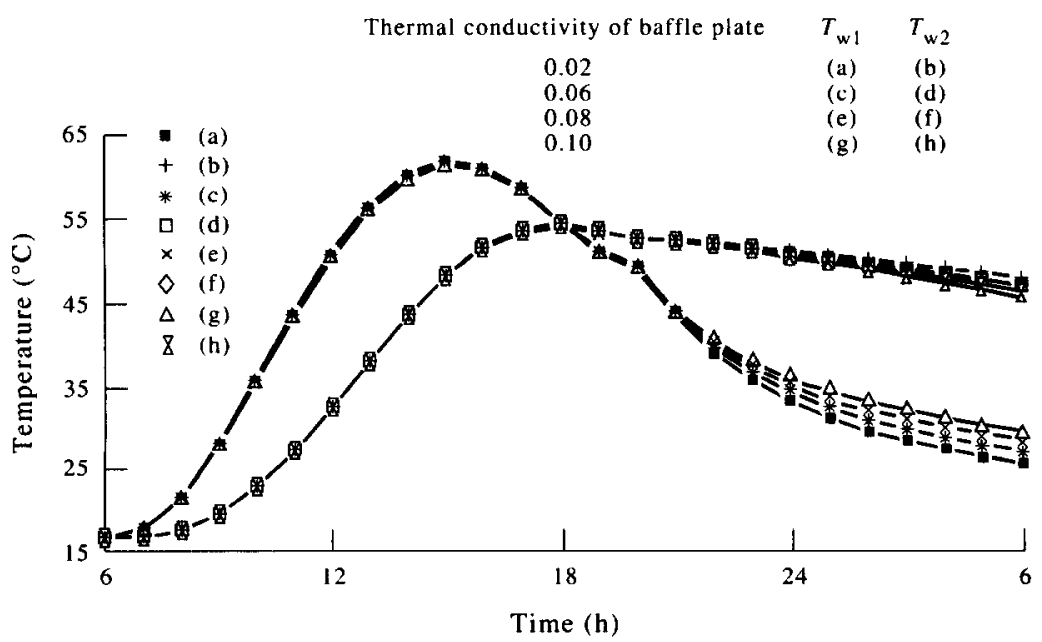

Fig. 6. Variation in water temperature with the thermal conductivity of baffle plate. 


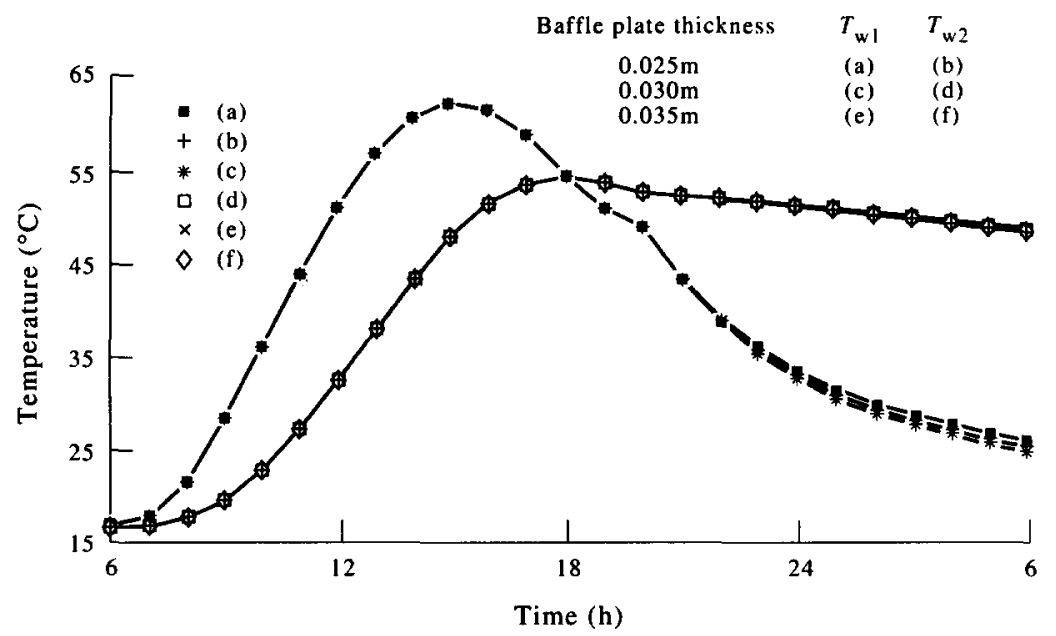

Fig. 7. Variation in water temperature with the thickness of baffle plate.

Figure 3 shows the variation in the water temperature with a constant flow rate. The constant flow rate is $5 \mathrm{~kg} / \mathrm{h}$, and the flow durations considered are $(6.0-6.0),(6.0-18.0),(8.0-18.0)$ and (18.0-6.0).

Figure 4 shows the effect of the vent area on the water temperature in the heater. By changing the vent area, only marginal changes in the water temperature are noted. As the vent area is increased, the quantity of heat transferred from the upper column to the lower by convection is increased, therefore as the vent area increases, the temperature of the upper water column falls, and the temperature of the lower water column increases by an appreciable amount.

Figure 5 shows the variation in the water temperature of the two columns by changing the mass ratio (keeping the total water mass in the tank constant) in the two columns. By changing the mass ratio in the two columns, there are only slight changes in the temperatures of the water. So, the mass ratio in the two columns only affected marginally the performance of the system.

Figure 6 shows the effect of the thermal conductivity of the baffle plate on the performance of the heater. It is observed that, as the thermal conductivity of the baffle plate is increased, there is no appreciable change in the temperature of the water of either column.

Figure 7 shows the effect of the thickness of the baffle plate on the performance of the heater. As the thickness of the baffle plate increased from 0.025 to $0.035 \mathrm{~m}$, there is no appreciable change in the water temperatures of either column. It is thus concluded that the presence of the baffle plate enhances the performance of the system, especially during the off-sunshine hours. The thickness and thermal conductivity of the baffle plate are immaterial.

\section{REFERENCES}

1. J. Prakash, H. P. Garg, R. Kumar and S. C. Kaushik, Proc. Nat. Sol. Energy Conv. (NSEC'92). I.I.T. Delhi (28--31 December 1992).

2. S. C. Kaushik, R. Kumar, H. P. Garg and J. Prakash, J. Heat Recovery System. In press.

3. J. Prakash, S. C. Kaushik, R. Kumar and H. P. Garg, Energy - The International Journal 19, 869 (1994).

4. A. Ecevit, A. M. AL-Shaiah and E. D. Apoydin, Sol. Energy 42, 253 (1983).

5. J. F. Van Straaten, Proc. 2nd Southeastern Conf. Applic. and Sol, Energy, Baton Rauge, Louisiana (1976).

6. G. N. Tiwari and N. K. Dhiman, Energy Convers. Mgmt 23, 151 (1983).

7. H. P. Garg and Usha Rani, Sol. Energy 29, 467 (1982).

8. H. P. Garg, Treatise on Solar Energy. Wiley, New York (1982). 